\title{
The national scenarios for emissions reduction in residential heating sector in Poland
}

\author{
Elżbieta Niemierka ${ }^{1, *}$, and Piotr Jadwiszczak ${ }^{1}$ \\ ${ }^{1}$ Wroclaw University of Science and Technology, Faculty of Environmental Engineering, \\ Wybrzeże Wyspiańskiego 27, 50-370 Wrocław, Poland
}

\begin{abstract}
Today's residential heating sector (RHS) in Poland is based mainly on fossil fuels combustion, both in individual and large-scale heat sources. The RHS emissions significantly contribute to the outdoor air quality deterioration, especially by low-stack emissions in the heating season. Following the example of other EU countries, the national scenarios for emissions reduction in RHS are an effective tool for outdoor air quality improvement. The scenarios contain a replacement of the existing heat sources in RHS with heat generation technologies in the scale of the country, like high-efficiency gas boilers, biomass boilers or heat pumps. The study takes into account today's RHS structure in Poland, the scenarios feasibility and achieved emissions reduction.
\end{abstract}

\section{The anthropogenic emission in residential heating sector}

In Poland, the residential heating sector (RHS) is based on fossil fuel combustion, both in individual heat sources (HS) and large-scale district HS, including heat-only boilers and combined heat and power plants (CHP). The average age of individual HS in Poland is almost 10 years and the technical condition of boilers, quality of fuels, combustion processes and emissions are here completely out of control [1]. The large scale district HS and CHP can supply a large number of consumers and offer lower emissions due to highefficiency and effective exhaust treatments.

Today's RHS in Poland consumes $550 \mathrm{PJ} /$ year, representing 21\% of total heat demand in Poland, and is responsible for emissions of 36\% of sulfur oxides (SOx), $64 \%$ of carbon monoxide (CO), $40 \%$ of total suspended particles (TSP) and $87 \%$ of polycyclic aromatic hydrocarbons [2-3].

The poor outdoor air quality problem is associated not only with emissions of wellknown $\mathrm{CO}_{2}$ and other greenhouse gases but also with the emission of SOx, nitrogen oxides (NOx), CO, TSP, benzo $(\alpha)$ pyrene $(\mathrm{B} \alpha \mathrm{P})$ etc. A particular threat is the low-stack emissions from individual HS in the RHS, which result in smog during the heating seasons. The high risk of smog occurs in urban areas with a high heat demand density and a large number of small fossil fuels HS. In 2014, $92 \%$ of the world population was living in places where the World Health Organization air quality guidelines levels were not met [4].

\footnotetext{
*Corresponding author: elzbieta.niemierka@pwr.edu.pl
} 
Poor outdoor air quality concerns not only Polish cities. The occurrence of the Big Smoke of London in 1952 led to the creation the Clean Air Act 1956 as a tool to combat smog. Since then, by prohibiting from using coal-fired boilers, replacing power plant outside urban areas, increasing the height of chimneys of local emitters, introducing fees and restricting the movement of high emissions vehicles in the cities centre, it has been able to improve ambient air quality [5]. Analogous regulations are in force and benefit in many European cities, for example in Vienna. It promotes buildings energy performance improvement and extends district heating system. It resulted in a reduction of TSP (PM10) by up to quarter and elimination exceed values [6]. These examples indicate that central, comprehensive scenarios to combat smog are an effective tool and bring more benefits than voluntary programs directed to individuals [7]. It is evident, that the common solutions are needful in Poland, in the scale of the region and even the whole country, to improve the outdoor air quality.

\section{Emissions in Polish RHS}

As mentioned above the heat demand in RHS in Poland amounts to $550 \mathrm{PJ} /$ year. The heat is generated in individual and central HS using different fuels (coal, lignite, coke, wood, natural gas, LPG and oil) and energy carriers (district heating and electricity). Fig. 1. shows the share structure of fuels and energy carriers in the Polish RHS [8-10] and the emissions factors respectively [1, 11-12]. Fuels like natural gas, LPG and fuel oil have low emissions ratios and fuels like coal, lignite, coke and wood are characterised by higher factors, especially in SOx, CO, TSP and $\mathrm{B} \alpha \mathrm{P}$. It should be noted that the wood can be regarded as a renewable energy source, but it also causes local emissions, despite a zero balance $\mathrm{CO}_{2}$, which was included.

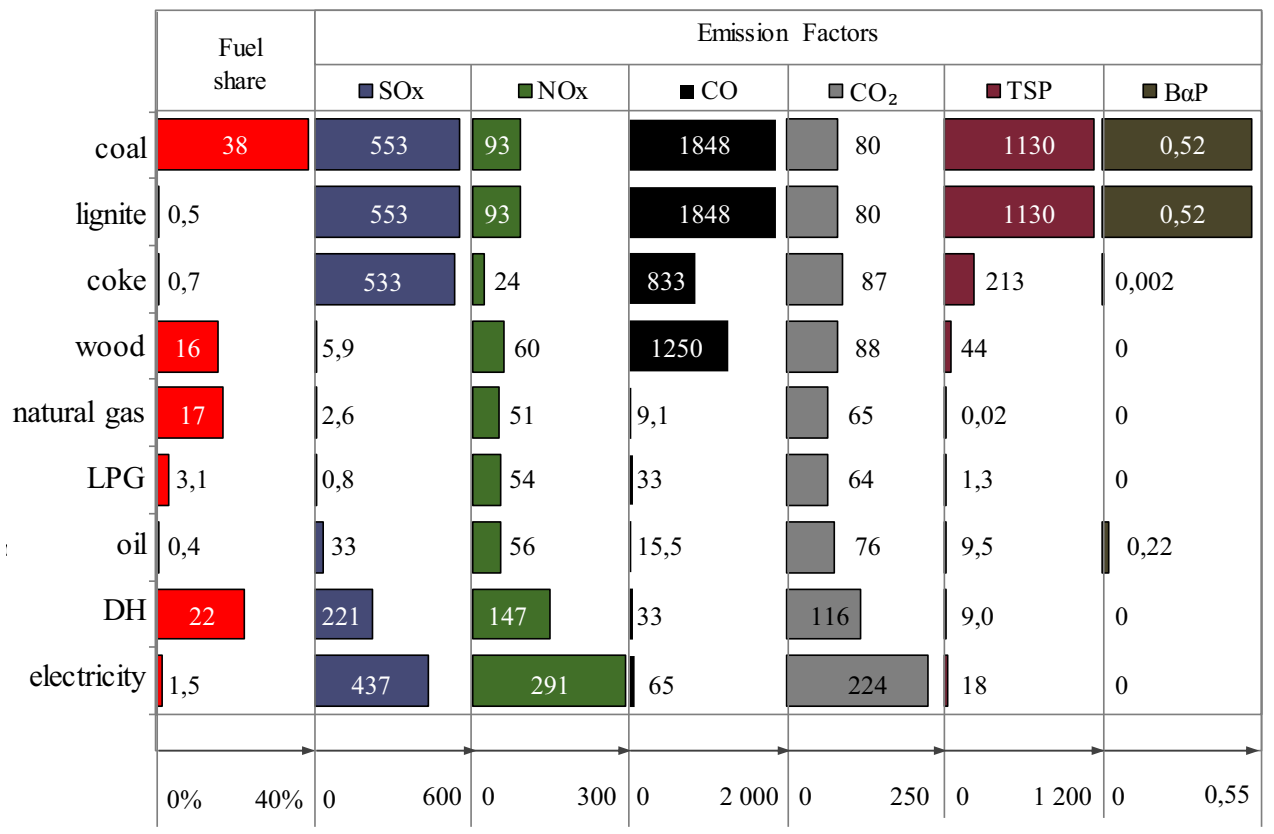

Fig. 1. The shares of fuels and energy carriers in RHS (in \% of heat demand) and emission factors resulting from the fuel combustion or energy carrier consumption by the final customer (in $\mathrm{Mg} / \mathrm{PJ}$ and for $\mathrm{CO}_{2}$ in $\mathrm{Gg} / \mathrm{PJ}$ ) (based on [1, 8-12]). 
Emissions in the RHS may be limited in two main ways - by reducing heat demand (building refurbishment or thermo-modernization) [1] and by replacing HS with high efficient devices [13-14], that consume low-emission fuels or with individual renewable energy sources. It should be noted that there is no one universal scenario to improve outdoor air quality by the emissions abatement at RHS. It is required to analyse the current state and to identify the applicable scenarios of changes. As mentioned above, the national scenarios are the best solution for the effective reduction of emissions in RHS. The development of proper national scale scenarios necessitates better knowledge of the energy sector structure, the heat demand profiles, the heat generation technologies, the fuels and energy carriers mix, the emissions factors etc. The paper presents the 7 developed exemplary scenarios of national scale changes in the structure of heat supply in RHS in Poland, to eliminate the smog risk and improve the outdoor air quality. The target is to decrease both the low-stack emission (LE) and total emission (TE) in RHS, mainly in individual HS. The LE means the significant amount of contaminants emitted directly into the neighbourhood and has a considerable impact on people's lives and it contributes to their health status. The TE affects outdoor air quality in the scale of the country and above borders, and to changes in the global environment.

\section{The national scenarios}

The national scenarios have the greatest impact on the choice of strategy changes leading to the emissions reductions. Therefore 7 national scenarios were developed and compared to the current emission in Polish RHS.

Nowadays in Poland heat-only boiler plants, power plants, CHP, district heating systems and individual boilers are mainly based on coal, lignite and wood combustion, accompanied by high emissions factors. Fig. 2. shows the shares of fuels combustion or energy carriers consumption in particular pollutants emission. Almost entire emissions of cancerogenic $\mathrm{B} \alpha \mathrm{P}$ and TSP is connected with LE, caused by coal combustion. A large share of pollution takes wood $\left(\mathrm{CO}_{2}, \mathrm{CO}\right.$ and $\left.\mathrm{NOx}\right)$ and coal-based $\mathrm{HS}\left(\mathrm{CO}_{2}, \mathrm{NOx}\right.$ and $\left.\mathrm{SOx}\right)$.

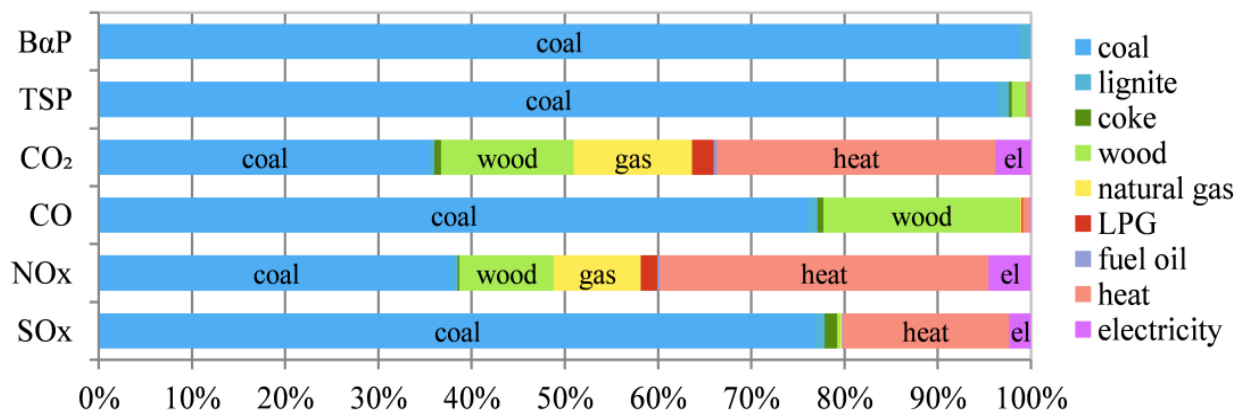

Fig. 2. Current shares of fuels and energy carriers in emissions from Polish RHS.

All the proposed in national scenarios modifications will be a concern in the individual HS sector as causing the greatest smog risk. They do not include the upgrading in gas, oil, district heating and electricity HS, due to its good efficiency or small share in current RHS emission. All national scenarios are presented in detail in Table 1 and contain a replacement of all individual HS based on fossil fuels combustion with other, more effective heat generation technologies like high-efficiency coal boilers, biomass wood boilers, gas boilers, heat pumps and district heating plus heat pump mix (Fig. 3.). The study takes into account today's structure of energy sector and RHS sector in Poland (Fig. 2.), the scenarios 
feasibility and achieved reductions of emissions. The results of each scenario will be shown as the calculated LE and TE reductions, referenced to the current state.

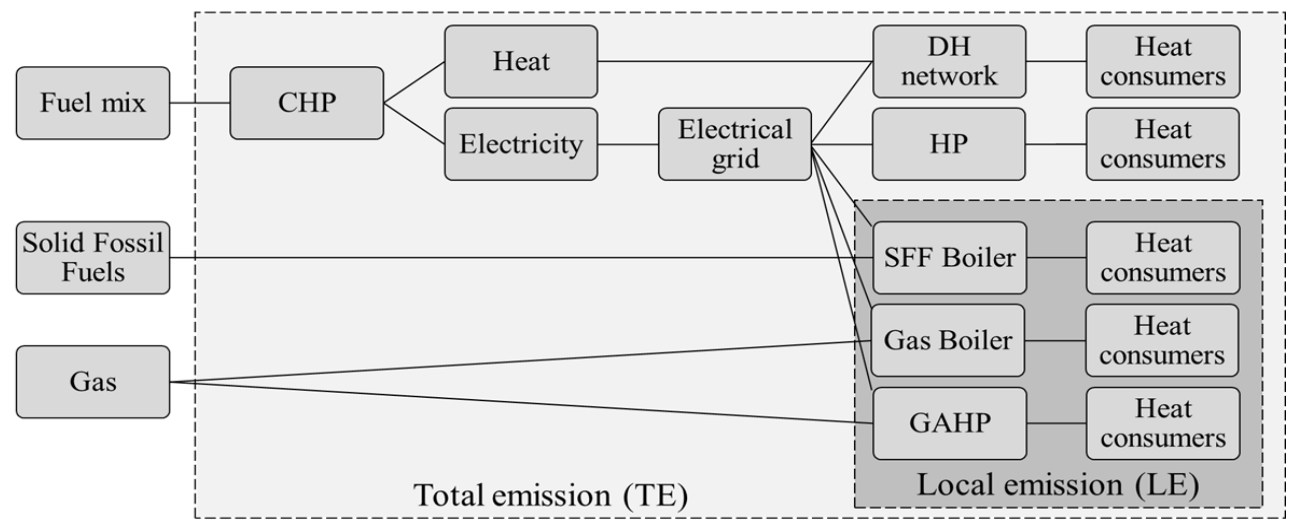

Fig. 3. The energy and heat flow diagram for LE and TE calculation in all scenarios.

In each scenario, the LE and TE were calculated as described below, according to Fig. 3., Eq. 1 and Eq. 2. The calculation diagram as energy and heat flow in all scenarios is shown in Fig. 3. The scheme takes into account the all technical factors related to RHS, energy sector, fuels and energy carriers mix, LE and TE in Poland.

The LE was calculated as the sum of $\mathrm{LE}_{\mathrm{k}}$ of pollutants emitted from all kind of local HS predicted in national scenario. The LE of the k-th contaminants $\left(\mathrm{LE}_{\mathrm{k}}\right)$ are associated with individual HS, and takes into account the share of the i-th fuel $\left(\mathrm{m}_{\mathrm{F}, \mathrm{i}}, \%\right)$ [8-10], the space heating participation ( $\left.\mathrm{n}_{\text {heating, },}, \%\right)[3]$ in residential sector heat demand (HD, PJ/annum), the average efficiency of HS $\left(\eta_{i}, \%\right)[1,13-14]$ and the emission factor from i-th fuel of $k$-th pollutant $\left(\mathrm{EF}_{\mathrm{i}, \mathrm{k}}\right.$, ton/PJ) [11] - Eq.1. The LE does not include emissions associated with grid electricity and district heating consumption, due to transferring of emissions to the central plants away from the consumers.

$$
L E_{k}=H D \cdot \sum\left(m_{F, i} \cdot n_{\text {heating }, i} \cdot \eta_{i} \cdot E F_{i, k}\right)
$$

The TE is related to both local and national emission, and additionally includes the share of the $\mathrm{j}$-th energy carrier $\left(\mathrm{m}_{\mathrm{EC}, \mathrm{j}}, \%\right)$ [8-10], the space heating participation ( $\left.\mathrm{n}_{\text {heating, }}, \%\right)[3]$ in residential sector heat demand (HD, PJ/annum), the average efficiency of HS $\left(\eta_{\mathrm{j}}, \%\right)$ [1,13-14], the efficiency of energy carrier generation $\left(\eta_{\mathrm{j}, \mathrm{g}}, \%\right)$ and transmission $\left(\eta_{\mathrm{j}, \mathrm{t}}, \%\right)$ [15-16], and the emission factor $\mathrm{j}$-th energy carrier of $\mathrm{k}$-th pollutant $\left(\mathrm{EF}_{\mathrm{j}, \mathrm{k}}\right.$, ton/PJ) [12]. The $\mathrm{EF}_{\mathrm{i}, \mathrm{k}}$ value is dependent on energy generation technology and transmission efficiency as well as on usable and excess energy ratio in CHP plant. Contemporary HS, both conventional and renewable, require an auxiliary power supply $\left(\mathrm{AP}_{\text {el.,k }}, \mathrm{PJ}\right)$ [17]. In Polish RHS it is typically grid electricity, which causes an additional amount of contaminants. Consumption of grid electricity moves the emissions to the central power or CHP plants, which increases the national TE without increasing the risk of smog. According to the above dependencies was created equation that was used in the calculations of emissions for all national scenarios - Eq. 2.

$T E_{k}=L E_{k}+\sum\left(A P_{e l, k} \cdot E F_{j, k}\right)+H D \cdot \sum\left(m_{E C, j} \cdot n_{\text {heating }, j} \cdot \eta_{j} \cdot \eta_{j, g} \cdot \eta_{j, t} \cdot E F_{j, k}\right)$ 
The proposed modifications in 7 analysed scenarios are described in Table 1 . The names of scenarios come from the main change applied in RHS. All scenarios were compared in terms of emissions, calculated on the basis of Eq. 1 and Eq. 2.

Table 1. Characteristic national changes scenarios.

\begin{tabular}{|l|l|}
\hline $\begin{array}{c}\text { National } \\
\text { scenario }\end{array}$ & \multicolumn{1}{c|}{ Characteristic of national scenario } \\
\hline 1. Base & Current state - current HD, and current HS structure in RHS \\
\hline 2. BR & $\begin{array}{l}\text { Reduced HD due to buildings refurbishment or thermo-modernization, } \\
\text { and current HS structure }\end{array}$ \\
\hline 3. Coal & Current HD and all SFF replaced with HE coal boilers (class V) \\
\hline 4. Wood & Current HD and all SFF replaced with HE wood biomass boilers (class V) \\
\hline 5. Gas & Current HD and all SFF replaced with HE condensing gas boilers \\
\hline 6. GAHP & Current HD and all SFF replaced with gas absorption heat pumps \\
\hline 7. HP & Current HD and all SFF replaced with electrically driven heat pumps \\
\hline 8. HP\&DH & $\begin{array}{l}\text { Current HD, all SFF replaced by mix of electrically driven heat pumps and district } \\
\text { heating system according to CHP heat and electricity generation ratio }\end{array}$ \\
\hline & Where: HE - high-efficient, SFF - solid fossil fuels \\
\hline
\end{tabular}

The effects of the national scenarios, calculated according to Eq. 1 and Eq. 2, are shown in the Fig. 4-7. Fig. 4. presents the reductions of fuels and energy carries consumption in RHS due to the improvement of individual HS efficiency and changes of fuels and energy carriers mix in following scenarios. The lowest consumption as compared to Base scenario corresponding to HP and HP\&DH, while the largest to Coal and Wood scenario. The fuels and energy carriers consumption is the base for LE and TE calculations in all national scenarios.

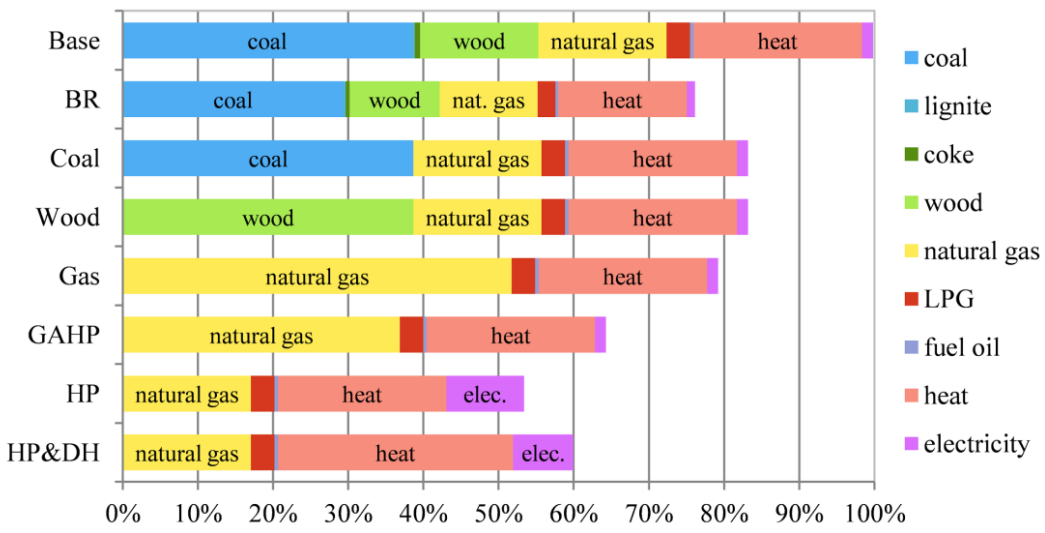

Fig. 4. The fuels and energy carriers consumption for all scenarios in relation to the Base.

Fig. 5. shows the relative reductions of pollutants calculated both in LE and TE for all national scenarios. In every scenario, the LE and TE will be reduced, which will be contributed to the outdoor air quality improvement. The scenario BR based only on the old buildings refurbishment, with no changes in fuels and energy carriers mix, results in $24 \%$ reduction of emissions (reduced to $76,3 \%$ in relation to the Base scenario). The calculation takes into account the statistical data on the age, the size of dwellings and the heat demand for all existing buildings in the Polish sector. The BR scenario predicts refurbishment of all 
buildings constructed before World War II, which constitute about $22 \%$ buildings in Poland, to the current energy standards [1].

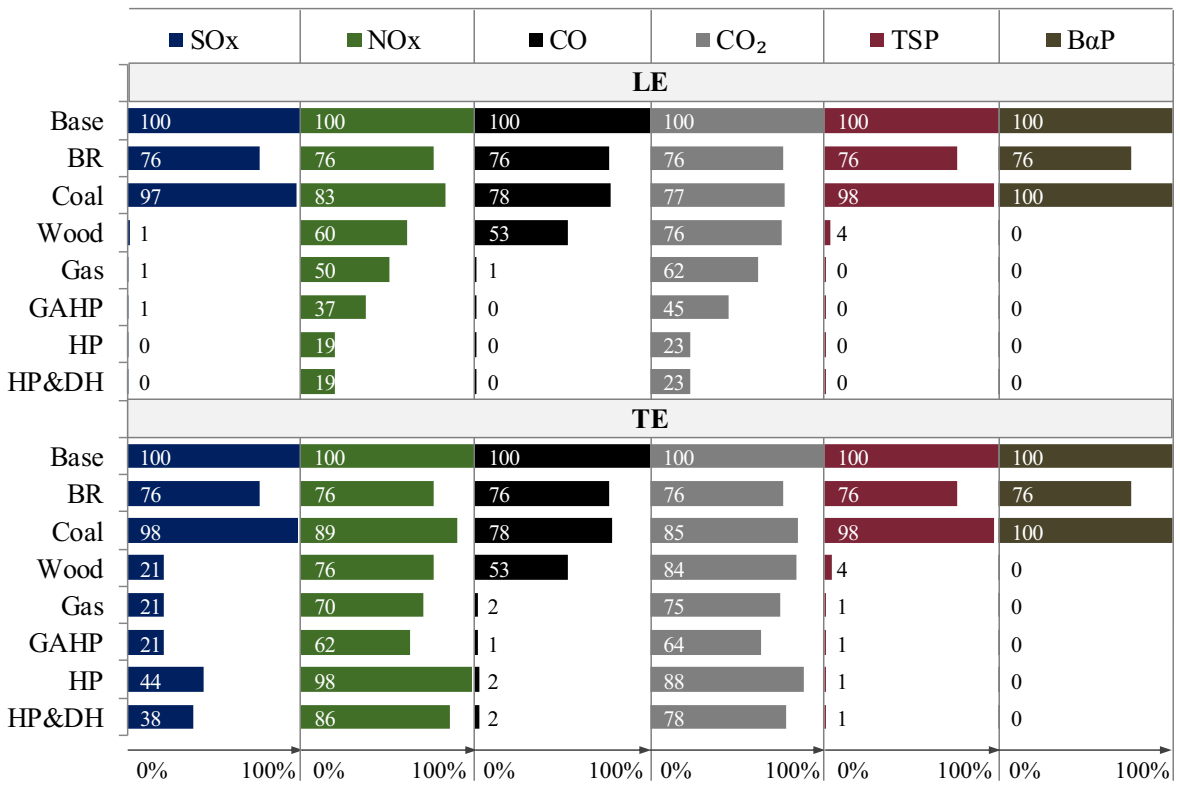

Fig. 5. Relative emissions of different contaminants in individual scenarios according to the Base.

The further scenarios predict replacement of all low efficient individual heat sources with high efficient heating technologies in the scale of the country. The Coal scenario comprises replacement of all individual HS based on solid fossil fuels with high-efficiency coal-burned boilers (V class) and results in only a limited decrease in LE pollutants such as $\mathrm{NOx}(83 \%), \mathrm{CO}(78 \%), \mathrm{CO}_{2}(77 \%)$. The changes are incommensurate to the scale of national changes in RHS.

The Wood scenario results in the lowest LE among solid fossil fuels individual HS. Reduction of low-stack emission of $\mathrm{CO}_{2}$ is similar to Coal, however, we notice significantly lower relative emissions of TSP (4\%), SOx $(1 \%)$ and $\mathrm{BaP}(<1 \%)$.

Application of natural gas condensing boilers (scenario Gas) eliminates the same compounds as burning of wood, while reducing of $\mathrm{CO}_{2}(62 \%)$ and $\mathrm{NOx}(50 \%)$, and does not emit $\mathrm{CO}(1 \%)$.

The best results can be achieved in GAHP scenario. Low emissions factors for natural gas and high efficiency of GAHP result in avoiding of CO, TSP, BaP, SOx and incomparable reductions of $\mathrm{CO}_{2}(45 \%)$ and NOx (37\%) emissions.

The HP scenario is one of the most effective in reducing $\mathrm{LE}$ of $\mathrm{CO}_{2}$ and $\mathrm{NOx}$ up to about $20 \%$ and eliminates other contaminants. Replace the fossil fuels with electricity generated in central plants will transfer emissions, what is evident in LE and TE changes. Apply a large amount of electrically driven heat pumps causes an increase the generation of excess heat in CHP units and raise the emissions up to $12 \%$ (for NOx). The use of a large amount of heat pump units in Polish energy sector should be associated with the increase of district heating consumers.

The HP\&DH scenario predicts a mix of individual heat pumps and district heating supply in best proportion for current heat and electricity generation sector in Poland (heatonly boilers, power plants and CHP units). The coal-based CHP in HP\&DH scenario will 
slightly diminish $\mathrm{NOx}(86 \%), \mathrm{CO}_{2}(78 \%)$ and eliminate the $\mathrm{CO}$, TSP, and $\mathrm{BaP}(<2 \%)$ emissions.

The relative reductions of TE for all scenarios (with equal weights of all contaminants) are shown in Fig. 6. The large worth means the significant decrease of TE in each scenario.

The LE and TE reductions in five most effective scenarios (Wood, Gas, GAHP, HP and HP\&DH) are present in Fig. 7. The great value means the meaningful reduction of emissions. It should be mentioned that the LE and TE reductions occur on the different levels in the same scenario. From LE and TE point of view, there are two groups of scenarios with the best emissions reductions. The heat pumps based scenarios (HP and $\mathrm{HP} \& \mathrm{DH})$ are characterised by a large reduction of LE and only small reduction of TE. The gas based scenarios are characterised by good decreasing both in LE and TE.

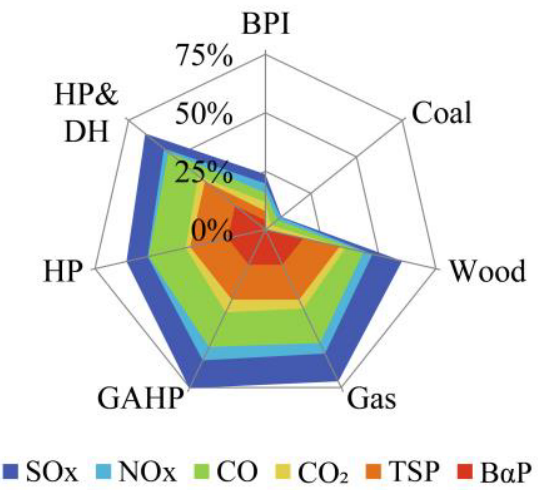

Fig. 6. The relative reductions in total emission for all scenarios (with equal weights of all contaminants - the total absence of emissions of one pollutant means a change from $12,5 \%$ to $0 \%$ ).

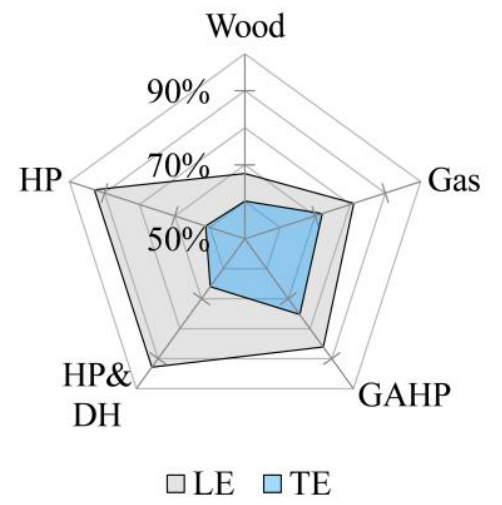

Fig. 7. The LE and TE reductions in the most effective scenarios. 


\section{Conclusions}

In Poland, air quality problem is caused mainly by low-stack emission. The proposed changes in individual heat sources sector will improve local air quality, both in local and country scale. Following the example of other countries, it was noted that national scenarios of changes in residential heating sector are an effective way to combat smog and poor air quality. The presented article can be used to design development path and created obligatory regulations that will reduce the emissions of pollutants and improve outdoor air quality. The presented national scenarios are monogenic, thus hardly realistic to implement. The real scenario will be a mix of fuels and energy carriers with different proportions dictated by their availability, pricing, government policy, etc. The analysis showed that the fuels with the greatest impact on emissions in Poland are coal and wood. Four of the seven presented scenarios are worthy of mention because they incomparably reduce the LE and TE. The highest TE reductions are achieved for GAHP (75\%), gas boilers $(72 \%)$ and by balancing the number of users electric heat pumps and district heating network in HP\&DH scenario (66\%). Exploit energy carriers can reduce LE by 93\%, however, a small share of renewable energy sources in Polish CHP negatively affects the overall balance - TE of contaminants allowing their limitation of only $66 \%$.

It is difficult to identify the best national scenario of reducing the LE and TE in Poland, but observation of change trends demonstrate that in the near future it will be HP\&DH based scenarios.

\section{References}

1. Instytut Ekonomii Środowiska, Efektywność energetyczna w Polsce. Przegląd (2015)

2. IOŚ-PIB, KOBiZE Krajowy bilans emisji SO2, NOx, CO, NH3, NMLZO, pyłów, metali ciężkich i TZO w układzie klasyfikacji SNAP i NFR (2015)

3. Central Statistical Office, Energy consumption in households 2012 (2015)

4. http://www.who.int/mediacentre/factsheets/fs313/en/

5. http://cleanair.london/wp-content/uploads/CAL-217-Great-Smog-by-GLA-20021.pdf

6. http://krakow.wyborcza.pl/krakow/1,44425,17728684,Wiedenskie nauki_dla_Krakow a_Jak_zrobic_miasto_skrojone.html

7. https://www.nfosigw.gov.pl/download/gfx/nfosigw/pl/nfoopisy/1207/1/17/poprawa ja kosci powietrza 20151109 100411.pdf

8. Central Statistical Office, Energy efficiency in Poland in years 2004-2014 (2016)

9. https://bdl.stat.gov.pl/BDL/

10. Central Statistical Office, Zużycie paliw i nośników energii w 2014r (2015)

11. https://krajowabaza.kobize.pl/docs/male kotly.pdf

12. http://kobize.pl/pl/fileCategory/id/28/wskazniki-emisyjnosci

13. Dz.U. 2015 poz. 376

14. PN-EN 303

15. Urząd Regulacji Energetyki, Energetyka cieplna w liczbach - 2014 (2015)

16. https://www.export.gov/article?id=Poland-Electrical-Power-Systems

17. Dz.U. 2015 poz. 376 